\title{
Inteligência artificial em sistemas de justiça: uma percepção baseada no Brasil
}

\section{Artificial intelligence in justice systems: a perception based on Brazil}

\author{
Paulo Henrique de Souza Bermejo ${ }^{1}$ \\ ${ }^{1}$ Universidade de Brasilia (UnB) Brasilia, DF, Brasil. ORCID: https://orcid.org/0000-0003-2680-8342
}

Autor para correspondência/Mail to: Paulo Henrique de Souza Bermejo, paulobermejounb@gmail.com

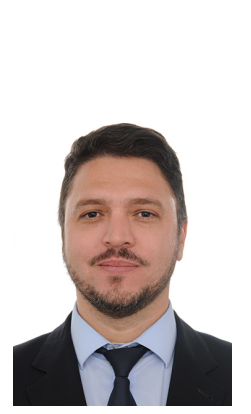

\begin{abstract}
Paulo Henrique de Souza Bermejo Graduado em Tecnologia de Processamento de Dados (FEMA/IMESA), Mestre em Engenharia de Produção (área de concentração em Inteligência Aplicada) e doutorado em Engenharia e Gestão do Conhecimento (UFSC). Realizou estágio de pós-doutorado em Inovação (Bentley University - EUA). Possui Certificação Executiva em Tecnologia e Inovação (MiT - EUA). É professor associado da Universidade de Brasília e coordenador do Núcleo de P\&D para Excelência e Transformação do Setor Público - NEXT/UnB. Atua como docente permanente e orientador no Programa de Pós-Graduação em Administração (Mestrado e Doutorado) da Universidade Federal de Brasília (UnB). Professor colaborador do Doutorado Profissional em Modelagem Computacional de Sistemas da Universidade Federal do Tocantins (UFT). Possui mais de 25 anos de experiência profissional exercendo funções nas áreas de gestão, engenharia, tecnologia e de inovação em empresas públicas e privadas. Seus principais interesses de pesquisa são Eficiência, Tecnologia e Inovação. É autor/co-autor de 7 livros, 24 capítulos e 98 trabalhos publicados em revistas científicas e eventos especializados. Antes de iniciar como docente da UnB, Paulo Bermejo atuou como Assessor de Estratégia e Inovação na Secretaria Executiva do Ministério da Educação entre junho de 2015 a maio de 2016 e como docente da Universidade Federal de Lavras (2006-2016), onde acumulou a função de Pró-Reitor Adjunto de Pós-Graduação (2009 a 2011). Foi bolsista de produtividade / Pesquisador mineiro FAPEMIG 2013-2015 e de Desenvolvimento Tecnológico e Científico do CNPq, categoria DTC-A 2016-2017.
\end{abstract}

Copyright (c) 2021 Bermejo. Todo o conteúdo da Revista (incluindo-se instruções, política editorial e modelos) está sob uma licença Creative Commons Atribuição 4.0 Internacional. Ao serem publicados por esta Revista, os artigos são de livre uso em ambientes educacionais, de pesquisa e não comerciais, com atribuição de autoria obrigatória. Mais informações em http://revistas.ufpr.br/atoz/about/submissions\#copyrightNotice.

\section{Resumo}

O Dr. Paulo Henrique de Souza Bermejo responde questões sobre inteligência artificial em sistemas de justiça a partir de uma perspectiva brasileira.

Palavras-chave: Inteligência artificial; Judiciário; Eficiência; Transformação digital.

\begin{abstract}
Dr. Paulo Henrique de Souza Bermejo answers questions about artificial intelligence in justice systems from a Brazilian perspective.
\end{abstract}

Keywords: Artificial intelligence; Justiciary; Efficiency; Digital transformation.

1. Qual a potencialidade da aplicação de inteligência artificial em sistemas de justiça? Poderia comentar sobre os principais avanços e o que estaria por vir?

A Inteligência Artificial (IA) tem se mostrado um recurso de alto valor agregado para diferentes setores e áreas, e em sistemas de justiça isso não é diferente. Entre os avanços, temos desde buscas mais inteligentes até a análise preditivas de processos e preenchimento prévio de peças jurídicas utilizando processamento de linguagem natural. Percebe-se que, no âmbito do Direito, escritórios e profissionais de advocacia estão mais avançados em termos do uso da IA em detrimento dos tribunais brasileiros.

Atualmente, já há muitas soluções de mercado disponíveis para esses escritórios e profissionais (ver, por exemplo: o radar de LegalTechs e LawTechs da AB2L em https://ab2l.org.br/radar-lawtechs/). No âmbito dos Tribunais de Justiça, apesar de ser de uso inicial mais tímido, já existem muitos tribunais que entenderam o potencial dessa tecnologia e estão realizando investimentos em IA para se tornarem mais eficientes. Entre as aplicações, destacam-se ações para distribuição eletrônica de mandados, resolução de conflitos por meio da conciliação e mediação, distribuição automática de processos, entre outros. De olho no potencial dessas soluções e na necessidade de unir esforços entre os Tribunais, o Conselho Nacional de Justiça (CNJ) está desenvolvendo a Plataforma Digital do Poder Judiciário (PDPJ), que deverá servir como um repositório de tecnologias digitais para o Judiciário.

2. Como profissionais, estudantes e pesquisadores deveriam se preparar para esta nova realidade?

Estudos recentes demonstram que atividades mais simples e rotineiras possuem maior probabilidade de serem substituídas por meio da tecnologia. No âmbito do direito, percebe-se que isso não é diferente. Para lidar com esse desafio, profissionais do setor devem buscar se especializar cada vez mais em suas áreas de atuação e buscar conhecimento interdisciplinar como de tecnologia e gestão. Ao fazer isso, a tecnologia deixa de ser uma ameaça e passa a se apresentar como um instrumento de apoio e suporte, de modo que esses profissionais sejam mais eficientes e efetivos em suas ações.

3. No seu ponto de vista, quais as principais barreiras a serem superadas para uma aplicação mais intensiva de inteligência artificial em sistemas de justiça? 
Digo que os principais desafios são de ordem cultural, estrutural e tecnológica. De ordem cultural, o desafio está em mostrar a essas instituições que a tecnologia não irá substituir magistrados ou interferir no seu processo de decisão. No âmbito estrutural, ainda há o obstáculo de processos que não estão digitalizados. Já em relação aos aspectos tecnológicos, há muitos tribunais que têm optado por desenvolver suas próprias soluções de IA, ao invés de contratar soluções já disponíveis ou que possam ser personalizadas por startups e empresas de tecnologia. Embora isso seja compreensível por razões de segurança de informação, entre outras, é notória a defasagem que essa estratégia pode provocar.

4. Considerando que sistemas de justiça possuem atores com características e finalidades diferentes, por exemplo, escritórios de advocacia, tribunais, delegacias de polícia, entre outros), como avalia a desigualdade entre eles no que tange às demandas, investimentos e barreiras?

Como já abordado, as características de instituições públicas e privadas levam as privadas a serem mais inovadoras e disruptivas do que as públicas. Em sistemas de justiça, essa lógica se repete. Há muitas startups e empresas de tecnologia que fizeram investimentos e hoje atendem a uma ampla gama de escritórios e profissionais, enquanto em tribunais essa realidade não é a mesma. Uma alternativa para ajudar os tribunais a evoluir mais significativamente em direção [a tecnologias avançadas como inteligência artificial] é a possibilidade de parceria com instituições de ensino e pesquisa - as quais dispõem de mão de obra altamente qualificada. Como exemplo, cita-se o sistema Victor do STF, desenvolvido pela equipe GPAM da Universidade de Brasília.

5. Neste debate reside a preocupação com o uso de inteligência artificial em diferentes aplicações nos sistemas de justiça. Em que medida essas preocupações são válidas?

Notam-se preocupações em termos de proteção de dados, capacidade de evolução dessas tecnologias pelos próprios tribunais, além de questões éticas. Tais inquietações são pertinentes, pois o potencial da inteligência artificial está diretamente associado à necessidade de leitura e análise de processos na íntegra, que carregam informações sensíveis e que não podem ser públicas. A evolução dessas tecnologias depende de profissionais altamente qualificados, que muitas vezes não estão ainda disponíveis no quadro dessas organizações, tornando-as dependentes de recursos externos. Já em relação ao aspecto ético da IA, trata-se de um dilema que vai além dos sistemas de justiça. Um exemplo clássico está em qual decisão um veículo autônomo deve tomar diante de uma situação inesperada sobre atropelar uma pessoa idosa ou um bebê.

\section{Há limites técnicos, legais e éticos relevantes?}

Como já relatei, há limites técnicos, pois o avanço da IA depende de investimento em desenvolvimento e treinamento das tecnologias. Em um cenário de escassez de recursos públicos, os escritórios de advocacia têm se destacado, pois o retorno é mais imediato por conta da opção por soluções já disponíveis e testadas pelo mercado. No âmbito dos tribunais, há a necessidade de customizar ou desenvolver novas soluções e isso demanda equipes altamente especializadas. No contexto brasileiro, isso se torna ainda mais desafiador, pois o sistema jurídico é próprio e muitas soluções de processamento de linguagem natural estão mais aptas para processar termos no idioma inglês, o que demanda às organizações brasileiras ações específicas de construção e customização. Sob os aspectos legais e éticos, há a Lei Geral de Proteção de Dados (LGPD) que traz uma segurança maior para as instituições interessadas em evoluir com essas tecnologias, mas toda a atenção é pouca, sobretudo no caso dos Tribunais, que administram dados sensíveis e que não podem ser compartilhados na sua totalidade.

7. Como avalia a situação do país a esse respeito? Estamos investindo na direção certa? O que podemos esperar no curto, médio e longo prazo?

O Brasil tem se destacado na construção de soluções digitais para apoio ao Direito. Essa evolução torna o trabalho de escritórios e advogados mais célere e eficiente. Já nos tribunais, a IA se apresenta como um instrumento para tornar o seu trabalho mais célere e reduzir o legado de julgamento de processos, mas, para isso, as barreiras precisam ser superadas e os esforços intensificados. A curto e médio prazos, podemos prever profissionais e escritórios capazes de predizer decisões judiciais com alto nível de assertividade, enquanto os tribunais intensificam a digitalização de processos e se estruturam para explorar a riqueza de informações que possuem em seus bancos de processos. A longo prazo, podemos esperar uma justiça mais ágil, transparente e acessível.

\section{REFERÊNCIAS}

Paz, B. C., Bermejo, P. H. S., Silva, S. (2020). Gestão de Processos como Ferramenta para o Aprimoramento da Gestão Pública: Estudo de Caso da Implantação em uma Organização Pública do Poder Judiciário. Encontro Nacional De Administração Na Justiça. Curitiba.

Soares, M. E., Bermejo, P. H. S., Santos, D. N. (2018). Justiça atrasada é justiça negada: o uso da inteligência artificial em prol da eficiência do ecossistema judicial. XXI Seminários de Administração da Faculdade de Administração da Universidade de São Paulo. São Paulo: FEA/USP. 


\section{REFERÊNCIAS}

Paz, B. C., Bermejo, P. H. S., Silva, S. (2020). Gestão de Processos como Ferramenta para o Aprimoramento da Gestão Pública: Estudo de Caso da Implantação em uma Organização Pública do Poder Judiciário. Encontro Nacional De Administração Na Justiça. Curitiba.

Soares, M. E., Bermejo, P. H. S., Santos, D. N. (2018). Justiça atrasada é justiça negada: o uso da inteligência artificial em prol da eficiência do ecossistema judicial. XXI Seminários de Administração da Faculdade de Administração da Universidade de São Paulo. São Paulo: FEA/USP.

Bermejo, P. H. S., Pagotto, D. P., Daltro, P. J. G., Sant'Ana, T. D., Vellenich, I., Rodrigues, A. A. M. (2019). Como impulsionar a eficiência organizacional a partir da gestão de processos? Brasília, DF: Evobiz.

Silva, N., Braz, F., Campos, T., Guedes, A., Mendes, D., Bezerra, D., Gusmão, D., Chaves, F., Ziegler, G., Horinouchi, L., Ferreira, M., Inazawa, P., Coelho, V., Fernandes, R., Peixoto, F., Maia Filho, M., Sukiennik, B., Rosa, L., Silva, R., Junquilho, T., Carvalho, G. (2018). Document type classification for Brazil's supreme court using a convolutional neural network. Proceedings of The Tenth International Conference on Forensic Computer Science and Cyber Law. São Paulo: HTCIA.

Araujo, L. de, Campos, P. H. de, Oliveira, T. E. de, Stauffer, R. R. R., Couto, M., Bermejo, S. P. (2018). LeNER-Br: A Dataset for Named Entity Recognition in Brazilian Legal Text. Lecture Notes in Computer Science. Springer International Publishing. pp. 313-323.

Como citar esta entrevista (APA):

Bermejo, P. H. de S. (2021). Inteligência artificial em sistemas de justiça: uma percepção baseada no Brasil. AtoZ: novas práticas em informação e conhecimento, 10(3), 1 - 3. Recuperado de: http://dx.doi.org/ 10.5380/atoz.v10i3.81967 